\title{
Improvements of safety conditions of unstable rock slopes through the use of explosives
}

\author{
M. Casale ${ }^{1}$, C. Oggeri ${ }^{2}$, and D. Peila ${ }^{2,3}$ \\ ${ }^{1}$ Pangea, Torino, Italy \\ ${ }^{2}$ DITAG, Politecnico di Torino, Italy \\ ${ }^{3}$ Italian National Research Council, ICAG - Section of Torino, Italy
}

Received: 8 January 2008 - Revised: 9 May 2008 - Accepted: 10 May 2008 - Published: 15 May 2008

\begin{abstract}
The paper discusses operations aimed at creating a safer natural or man made rock slope by artificially inducing the displacement of unstable elements by blasting. A detailed analysis of the problems with the use of explosives present when conducting these activities is carried out focusing on the advantages and disadvantages of this technology. The results of two examples of demolition of instable rock elements are presented and discussed thus providing suggestions for future blasting designs.
\end{abstract}

\section{Introduction}

Infrastructures such as roads and railways, as well as houses and buildings in mountainside areas are often threatened by rockfall events which can be very dangerous and sometimes cause fatalities. The most frequent causes of rockfall are mainly related to water, namely, rain, freeze-thaw, snowmelt, channel runoff, differential erosion, and springs or seeps and the growth of tree roots in crack, which can open fractures and loosen blocks of rock on the slope face and which is directly linked to the presence of water. These seven causes together account for about $70 \%$ of the rockfalls as was observes by California Department of Transportation which made a comprehensive study of rockfalls that occurred on the state highway system (McCauley, 1985). These results were confirmed by other authors such as Duncan and Norman (1996), Peckover and Kerr (1977), Giani (1992), and Wieczorek et al. (2008). The other major group of factors affecting stability are the geologic and geotechnical conditions at each site, namely, fractured rock, adverse dip of the joints and soil

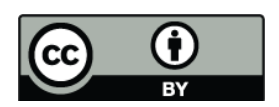

Correspondence to: D. Peila (daniele.peila@polito.it) decomposition. Finally earthquakes are a frequent and dangerous trigger of detachments from rock slopes.

When rock blocks are detached from the slopes they can move downward towards the infrastructures and interfere with them. Therefore for a rockfall protection design to be successful it is necessary first to define the area of risk located below the unstable rock slope (Evans and Hungr, 1993; Crosta and Agliardi, 2003; Guzzetti et al., 2003; Locatelli, 2005) and to forecast of the possible trajectories of the falling blocks (Giani, 1992) and secondly to chose and design the correct method that can: stabilize the unstable rock block directly on the slopes (Peckover and Kerr, 1977; Giani, 1992, Duncan and Norman, 1996; Oggeri and Peila, 2000), stop an already moving block or blocks through technological devices mainly located at the bottom of the slope (Peila et al., 1998, 2006, 2007; Pelizza et al., 2004), or conduct operations to remove the unstable elements (Cardu et al., 2004; DeWall, 1996; Goumans and Wallace, 1999; Philippon, 2001; Woolf and Goumans, 2002; Mackenzie, 2004).

This last intervention, the removal of unstable elements, is aimed at making a safer natural or man made rock slope by artificially inducing the fall of unstable elements without relevant changes of the geometrical features of the slope. The detachment of these elements (also called "scaling") can be performed by hand work; by mechanical devices, by chemical agents such as expanding mortars, or by the use of explosives.

Hand work often provides excellent results with minimal disturbance to the residual face, but is extremely slow and can sometimes be dangerous for the operators. Hand tools, such as levers and craw bars, when possible, light-weight pneumatic tools such as hammer picks, hammer drills, and rock splitters, and hydraulically operated tools are normally used. Obviously, the work starts from the top of the slope with the workers usually secured by a safety rope, such that the workers never have unstable rock elements above them.

Published by Copernicus Publications on behalf of the European Geosciences Union. 
But to work on a rock slope is anyhow a risky operation; the workers must exhibit athletic qualities, be experienced climbers, and physical training is necessary. Moreover, the operators remain in potentially risky locations even in the most critical instant: when the induced collapse occurs.

Mechanical tools, such as high energy impact hammers or single tooth tools mounted on the arms of hydraulic excavators, usually of the backhoe type, are often used. Their limit resides in the reach of the machine, which must operate from the existing road or from a purposely built access road. The machines can operate from above or from below the unstable rock. Particularly in the latter case, both the vertical and the horizontal reach are to be considered for a correct design since, as with the man work, the machinery remains in potentially dangerous locations during the induced collapse.

Drill and blast operations have been used to solve many rock slope stabilization cases and it does not suffer relevant limitations, apart from the unwanted effects of the explosion (flyrock, air blast, ground vibrations and rock damage). When drilling has to be done by hand with operators working on the slope the same difficulties are met as during scaling, but the workers are in a safe position during the blast. When medium weight machines are required, for example when large holes are needed, some access problem arise and it is necessary to install working platforms or use mechanical devices to lift the drilling device.

Expanding mortars poured inside a regular pattern of drilled holes have been widely used, but the design ay be complicated by the presence of open joints which can allow to the mortar to expand without creating the required pressure inside the hole; furthermore the required regular geometry of the drill holes may be difficult to create on irregular slopes or irregularly shaped rock blocks.

\section{Use of explosives and design criteria}

The design of a drill and blast demolition of an unstable rock block is normally conditioned by local features that dictate the blasting scheme geometry and firing. Therefore, apart from some general basic concepts, each application must be specifically treated and designed. For this reason the analysis of results obtained in past projects is particularly relevant since it provides useful basic data for future projects.

Single block demolition is normally designed as a conventional pop shooting, which is similar in principle to secondary blasting in quarries, and is often performed using expanding mortar rather than explosives.

On the contrary, when a large portion of rock is to be detached, the use of explosive is unavoidable and two main cases should be distinguished:

- The residual slope surface after the blast is an already existing discontinuity, detected and mapped before the blast. In this case, the operation is a fragmentation blasting. The rock volume is simply detached with fragmen- tation charges taking care the holes do not trespass the joint surface which must be preserved and protected. The blast round geometry is controlled by the geometrical position of the existing joints.

- The residual slope surface is created by the blast itself. In this case it is necessary to use a correctly designed "smooth blasting" (Langefors and Kihlstrom, 1967; Mancini and Cardu, 1995, 2001). Therefore it is necessary to create a regular pattern of "contour" or "smooth blasting" holes on the back of the blasted rock mass (Berta, 2000). Contour holes are usually designed on the basis of the static criterion (hole pressure/tensile strength of the intact rock match), and as a guideline the explosive load in the final line of holes the load should be in the range of 0.1 to $0.5 \mathrm{~kg} / \mathrm{m}^{2}$ of the face area (Duncan and Norman, 1996).

In the case of single isolated blocks, many irregular randomly placed free surfaces are present, and hole placement is dictated mainly by considering the worker's safety, i.e. the holes are placed where drilling is possible. The charges are not really designed, but rather imposed by the position of the round holes. In this case, small explosive charges are used and are usually calculated taking into account the "action radius criterion". The charge depends on the burden (the minimum distance from the center of the charge to the surface): $Q=k^{*} W^{3}$ where $Q$ is the mass of the charge, $k$ is a site coefficient depending by the round type of the rock and of the used explosive and $W$ is the burden (Langefors and Kihlstrom, 1967; Melnikov and Chesnokov, 1969; Mancini and Cardu, 1995, 2001).

The fragmentation requirements are, when possible, satisfied by increasing the number of holes rather than by increasing the charge of each single hole.

When large rock volumes are to be blasted the blast rounds can be (Fig. 1):

- parallel hole scheme, similar to those used in quarries for bench blasting;

- fan scheme that allows many holes to be drilled from a collaring area of reduced extent, thus reducing the need to repose the drilling machine.

As previously mentioned, usually in these cases the round consists of two functional groups of charges: production and contour. Production charges are designed on the basis of the "powder factor criterion". The charge is obtained by the product of the rock volume pertaining to the hole and a specific charge value ("powder factor"). Since test blasts to define the optimal "powder factor" usually are not possible, the design is based on values obtained from technical literature or similar cases.

One of the most important goals of the design of a blasting demolition is the certainty of the blasting effect, because 


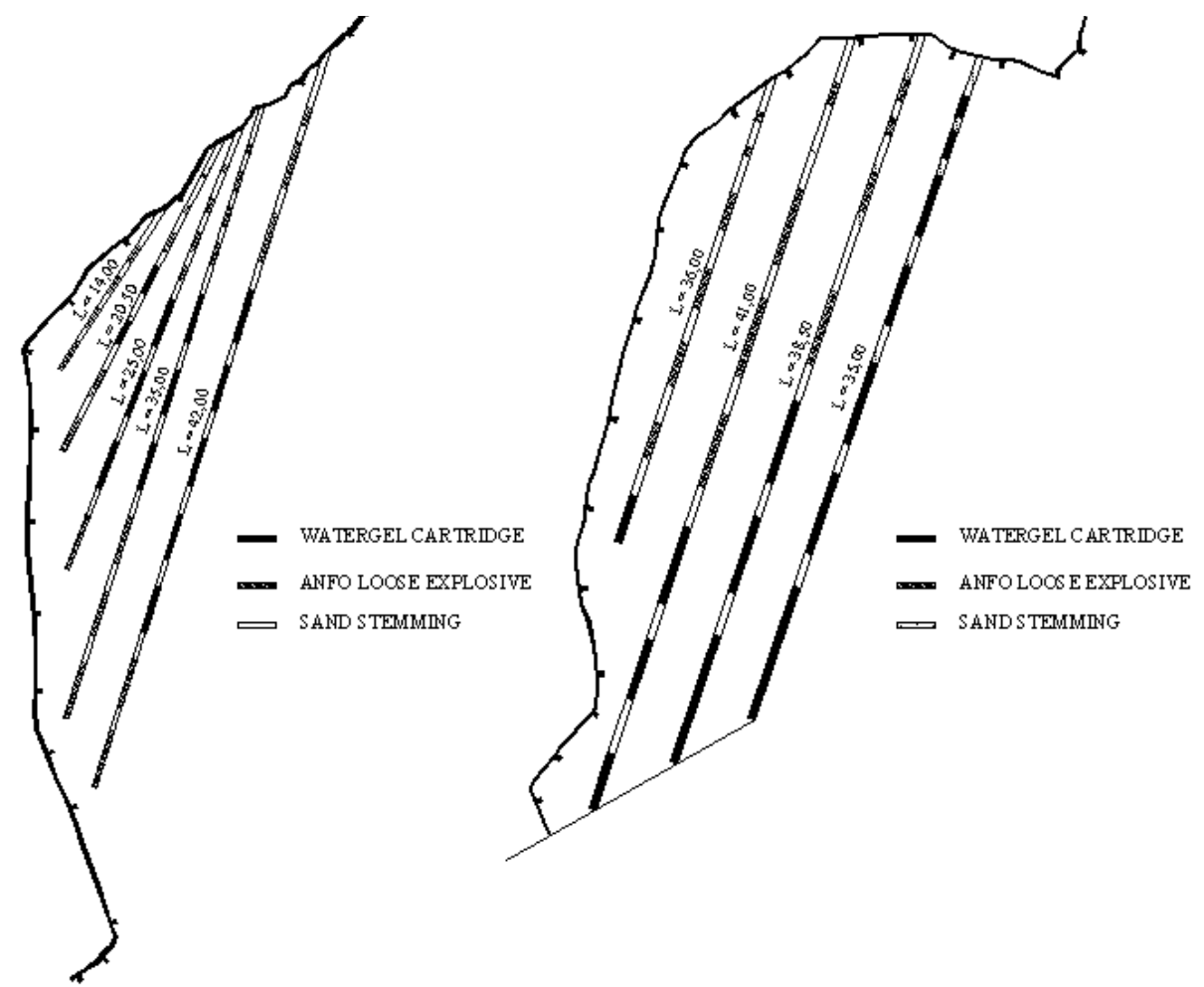

Fig. 1. Example of a fan blasting scheme and a parallel blasting schemes used to demolish about $57000 \mathrm{~m}^{3}$ of unstable rock mass threatening the town of Meiringen (Switzerland) (Rotzetter, 1977).

to correct the result of a bad blast can be very difficult, dangerous, or even impossible (this suggests the designer raise the powder factor to the upper limits but, in doing so several other problems will be created such as flyrock).

Dynamites are the most common type of explosives used, but less powerful explosives such as ANFO with a dynamite booster, are widely used.

Drilling is the most critical stage of the operation and is directly linked with the accessibility of the job sites. When hand drilling is carried out by suspended workers the drilling diameter cannot be bigger than $30 \mathrm{~mm}$ and the maximum length is around $2.5 \mathrm{~m}$.

Heavier drills must be used for larger diameters (50$90 \mathrm{~mm}$ ) and/or longer holes are needed; hole diameters in excess of $90 \mathrm{~mm}$ are seldom used. In these cases the drilling machines are often installed on a platform and the fan scheme is used. Lightweight machines are usually transported by helicopter and, in the case of rock slopes of limited height or of easy accessibility from the road drilling and charging can be performed by workers operating on self elevating baskets or platforms.

\subsection{Avoiding unwanted effects}

The most unwanted effect of blasting is damage caused by collapse of the blasted rock onto the road or the railway or, as most feared, into an inhabited area. Rails are usually removed before the blast and reinstalled after mucking while roads are protected by a layer of soil over the roadway paving. In most cases the most efficient protection is the fine fragmentation of the blasted mass. Sometimes, particularly to protect inhabited areas, reinforced earth embankments or provisional net fences are installed to contain the blasted rock mass. Such measures were installed in the cases of Meiringen (Switzerland) where a $57000 \mathrm{~m}^{3}$ of limestone rock were blasted (Rotzetter, 1977) and for the demolition of a $800 \mathrm{~m}^{3}$ rock wedge threatening the Quebec motorway (Canada) (Dorval, 1993).

Flying rock fragments cannot sometimes be completely avoided due to the presence of irregular and sometimes open joints. These rock fragments can fly very far. Wrapping the block with cable mesh has been successfully used for demolition of single blocks and small blasting operations, but the most important prevention measure is to orient the blast in such a way that flyrock, if anticipated, does not hit sensitive objects. The safe distance for operators should be increased with respect to normal blasting operations in quarries and is often raised up to $500 \mathrm{~m}$. Insurance of nearby existing houses is a common practice.

Ground vibrations are a serious problem when a triggering action on nearby unstable rock masses are feared. Usually a safe peak particle velocity (PPV) value is assumed, 


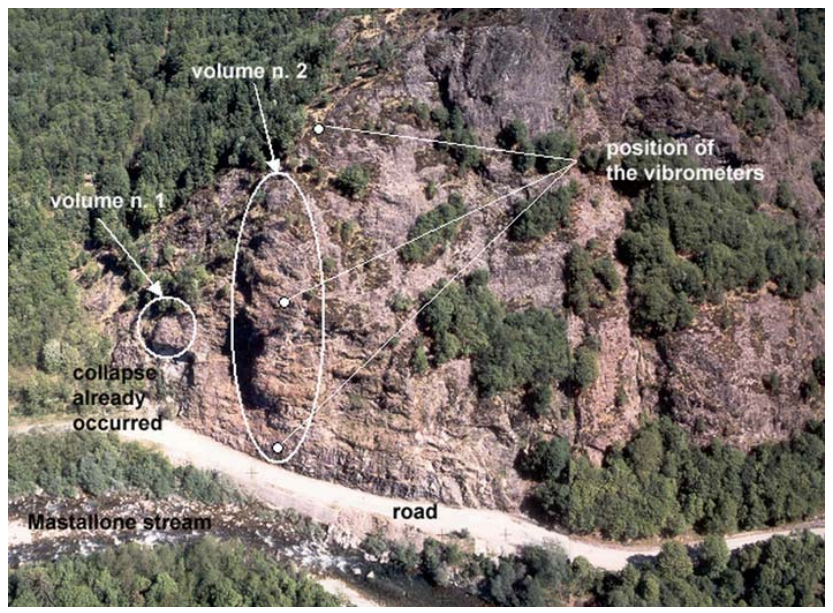

Fig. 2. Panoramic view of the unstable rock slope on the Mastallone valley (North of Italy).

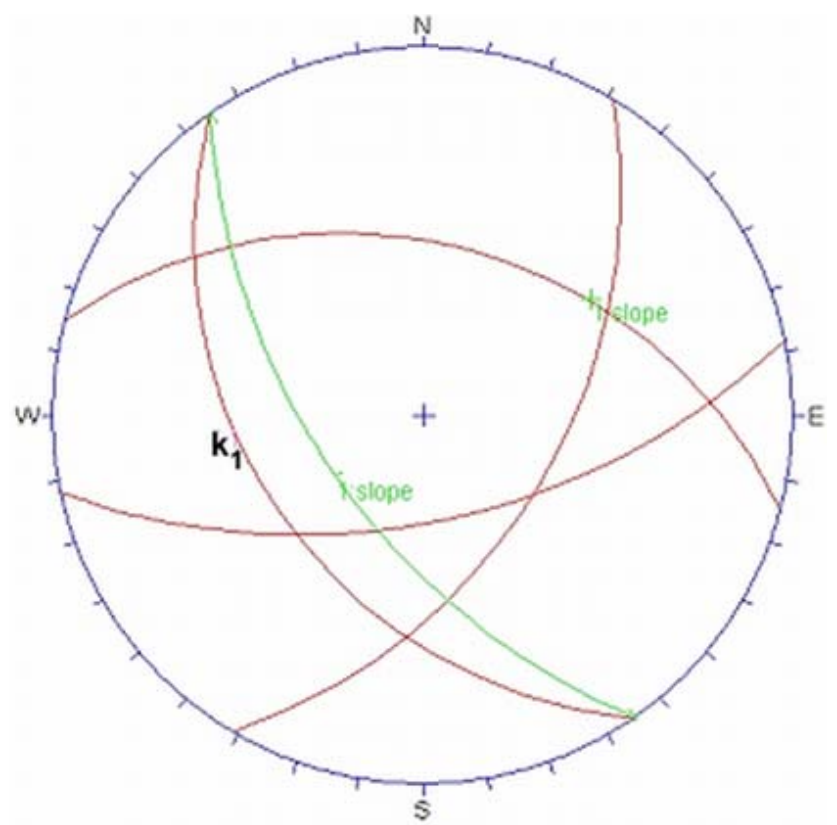

Fig. 3. Stereoplot of the structural condition in the area of volume n. 1. The planes represent the centers of measured pole concentrations.

predetermined and obtained by reducing the instantaneous charge blasted for each delay.

Up to now, general rules have neither been proposed nor enforced, and even the use of PPV as an indicator of the intensity of the disturbance of nearby rocks is debated.

Often the same peak particle velocity proposed by national standards to protect sensitive buildings is imposed and limit equilibrium analysis considering the vibrations as usually done for the stability analysis in seismic areas are performed.

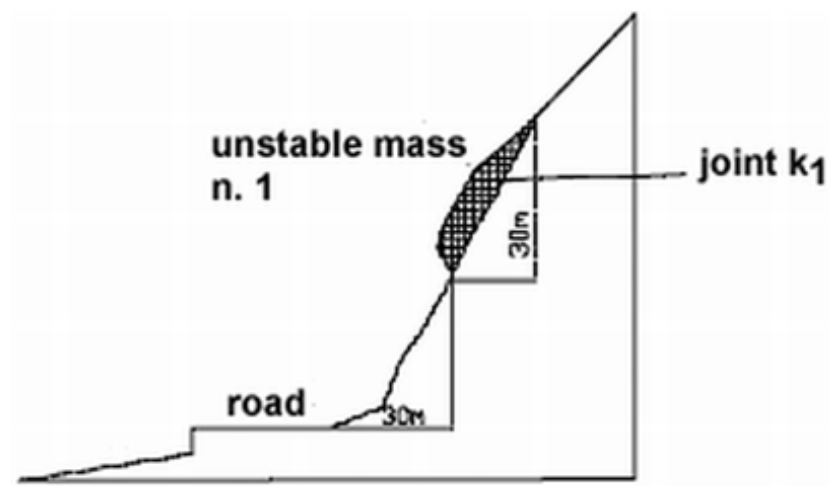

Fig. 4. Cross section of the rock volume n. 1 .

\section{Analysis of case histories}

Two relevant examples have been selected to illustrate the problems that can be encountered when a blasting solution to improve the safety of a road is chosen. The obtained results are presented and discussed thus providing data which can be used for similar designs.

\subsection{Case history 1}

This example describes the demolition of a volume of $2500 \mathrm{~m}^{3}$ (n. 1) overhanging a local mountainside road in the North of Italy (Fig. 2). The slope is made of weathered gabbric rock with uniaxial compressive strength of $90 \mathrm{MPa}$ and tensile strength of $8.5 \mathrm{MPa}$. Before the rock slope stability intervention this stretch of road was subjected to a systematic collapse of rock blocks of various sizes. Particularly critical was the earlier collapse of $1000 \mathrm{~m}^{3}$, from just below of the rock volume $n .1$ induced by a planar slide on a joint $\left(k_{1}\right)$ with a dip between $50-60^{\circ}$ and a dip direction parallel to the slope (Figs. 3 and 4).

The geostructural survey had shown the presence of many different planar and wedge sliding phenomena induced by existing joint patterns in the area. Particularly relevant for the blasting design of volume $n$. 1 was the presence of another rock volume (named n.2 in Fig. 2) of about $12000 \mathrm{~m}^{3}$ lying on joint $k_{1}$ which was in a stable condition due to the presence of many rock bridges on the joint. It was critical to prevent the disturbance of this mass by blast-induced vibrations.

The technical possibilities to eliminate the risk to the road due to the presence of the unstable rock volume n. 1 were to either build concrete columns to statically support the weight, use a pattern of tensioned anchors, or to perform blasting operations. Since the road is in a touristic area, the environmental impact of the concrete columns was not acceptable to the municipality, and the cost of the tensioned anchors was much higher that the cost of a blast demolition; therefore the blasting solution was chosen. 


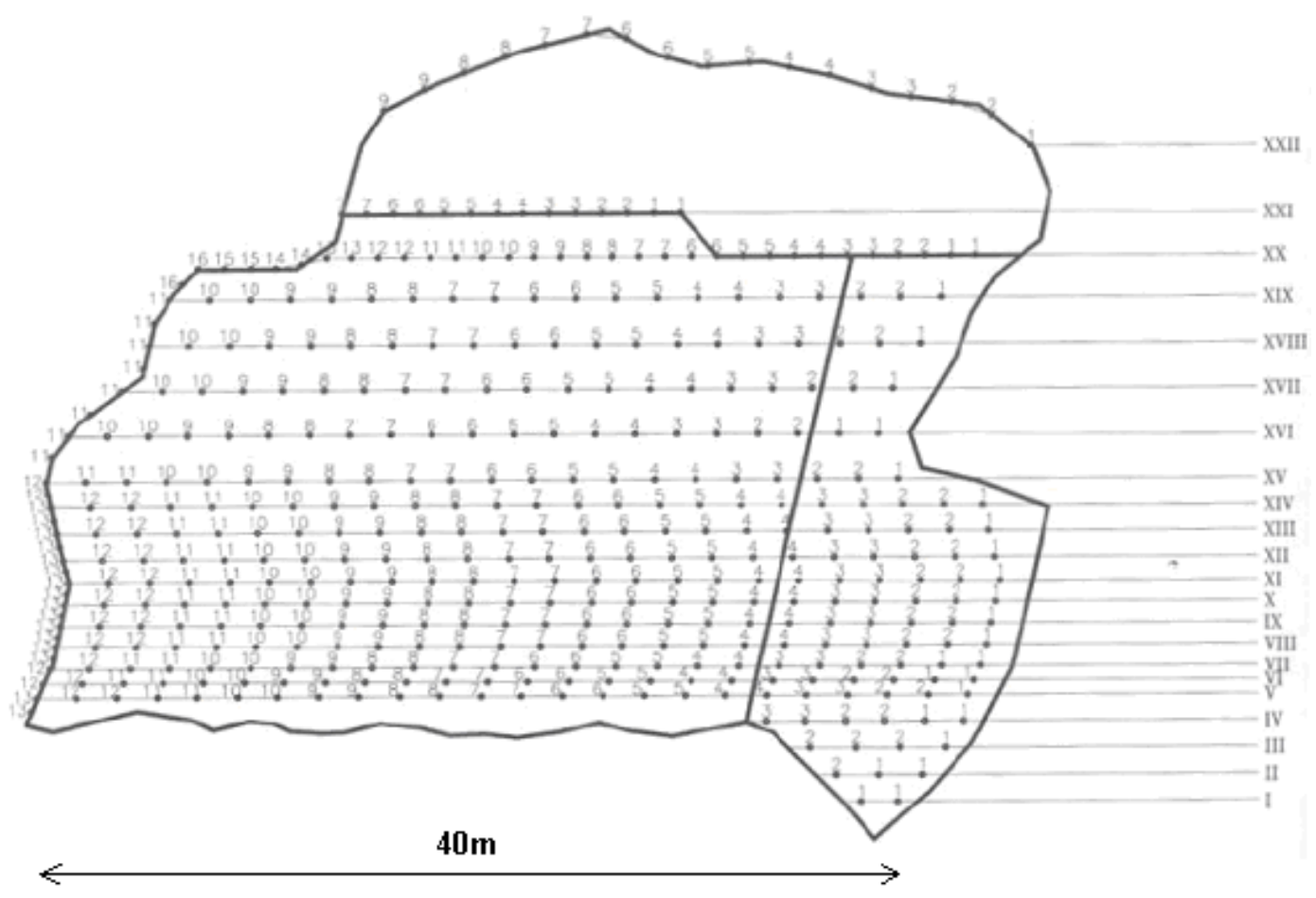

Fig. 5. Front view of the blasted round of volume n. 1. The Roman numbers indicates the various blasting lines which were blasted using a delay of $250 \mathrm{~ms}$ while the Arabic numbers indicate the microdelays used along each blasting line.

The blast was designed according to the "powder factor" criterion, assuming a specific consumption of $0.24 \mathrm{~kg} / \mathrm{m}^{3}$. This value is in good agreement with the one used in the example of Meringen (Switzerland) reported by Rotzetter (1977) where $57000 \mathrm{~m}^{3}$ of limestone rock was blasted in four rounds with a powder factor of $0.3 \mathrm{~kg} / \mathrm{m}^{3}$. Mixed charges of slurry and gelatine dynamite in cartridges were used for the charging. The typical charge of a borehole consisted of 1 to 2 gelatine dynamite cartridges (booster) at the bottom of the hole, a quantity of slurry (varied in function with the length of the borehole), and $1 \mathrm{~m}$ sand stemming. A total charge of $600 \mathrm{~kg}$ of explosive was needed for the whole blast round and the road was protected with a soil mattress $1 \mathrm{~m}$ thick.

The geometrical design of the blast round and timing (Fig. 5) was defined taking into account the position of the sliding joint $\left(k_{1}\right)$ which had to be protected. The fine fragmentation necessary to facilitate mucking was obtained by toughening the drilling mesh with 430 holes with an average length of $2.6 \mathrm{~m}$ for a total length of about $1000 \mathrm{~m}$. A specific drilling of about $0.38 \mathrm{~m} / \mathrm{m}^{3}$ was adopted.

The holes were drilled sub-horizontally until they reached sliding joint $\left(k_{1}\right)$ partly from a suspended platform, and partly by suspended workers. Three days were used to prepare the blast.

To prevent excessive blasting vibrations on volume n. 2 a safe PPV limit of $8 \mathrm{~mm} / \mathrm{s}$ was imposed. This level is considered a safe value for houses in the German standard (DIN
4156). Trial blasts were designed and carried out to evaluate the maximum amount of explosive for each delay and a maximum instantaneous charge of $4.5 \mathrm{~kg}$ was chosen.

Due to the large number of delay times required to limit the amount of single charge and safety concerns induced by some electric lines nearby it was not possible to use an electric firing system. Therefore a Nonel system was adopted with 23 branches each of which was delayed by $250 \mathrm{~ms}$ (starting from the lower row) and along each row a maximum number of 16 microdelays were used (Fig. 5).

It should be noted that the blast lasted about $6 \mathrm{~s}$, which caused a serious concern for cut-offs and was avoided by carefully choosing the layout and positioning of the main Nonel branches.

The blast was performed successfully, exposing the sliding joint (Fig. 6) and remaining within the PPV limits for the nearby unstable rock portion. The blast was monitored by 3 seismographs (Fig. 2) and at the base of the slope near the road the measured maximum PPV value was $3.7 \mathrm{~mm} / \mathrm{s}$ while in the middle of the rock mass $\mathrm{n} .2$ the measured value was $7.8 \mathrm{~mm} / \mathrm{s}$ and in the upper and stable part of the slope it was $4.8 \mathrm{~mm} / \mathrm{s}$.

\subsection{Case history 2}

This case refers to the demolition of an unstable monolithic slab of porphyry rock about $10 \mathrm{~m}$ wide, $33 \mathrm{~m}$ high, 2-6 m thick and with a global size of about $1300 \mathrm{~m}^{3}$ that threatened 


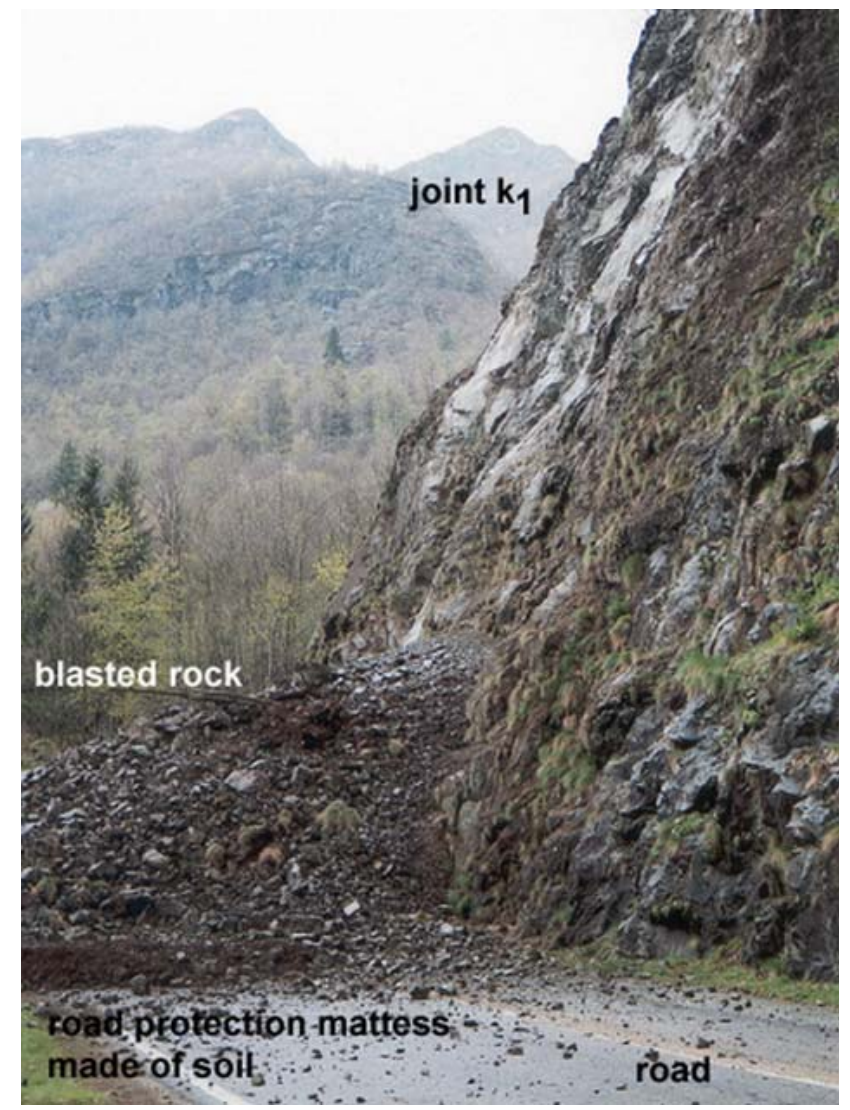

Fig. 6. Result of the blast. It is possible to see the joint k1 that was behind volume $n .1$ and the good fragmentation of the blasted rock.

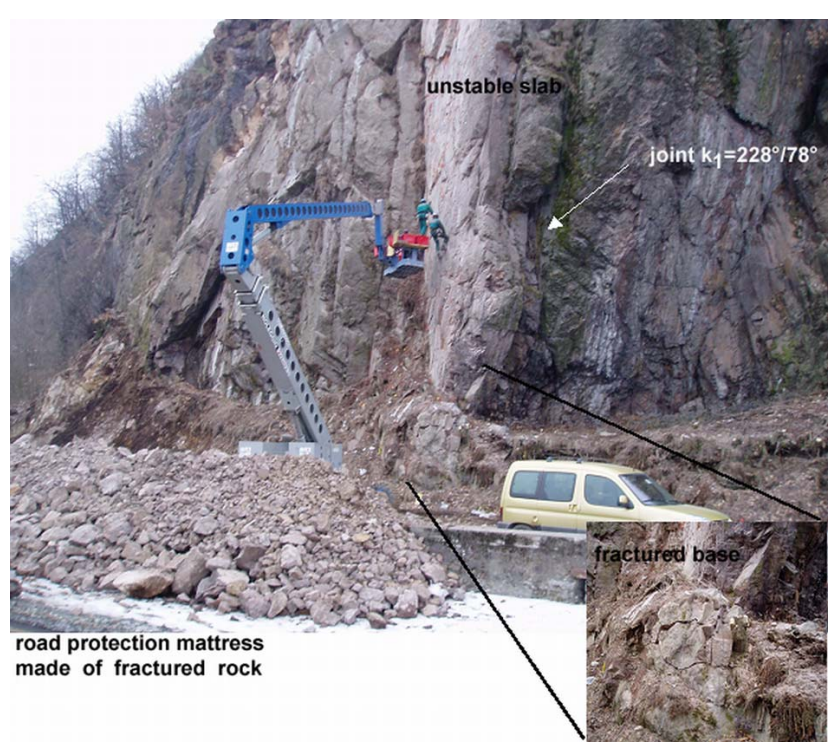

Fig. 7. Detail of the unstable slab and of the fractured rock portion at its base.

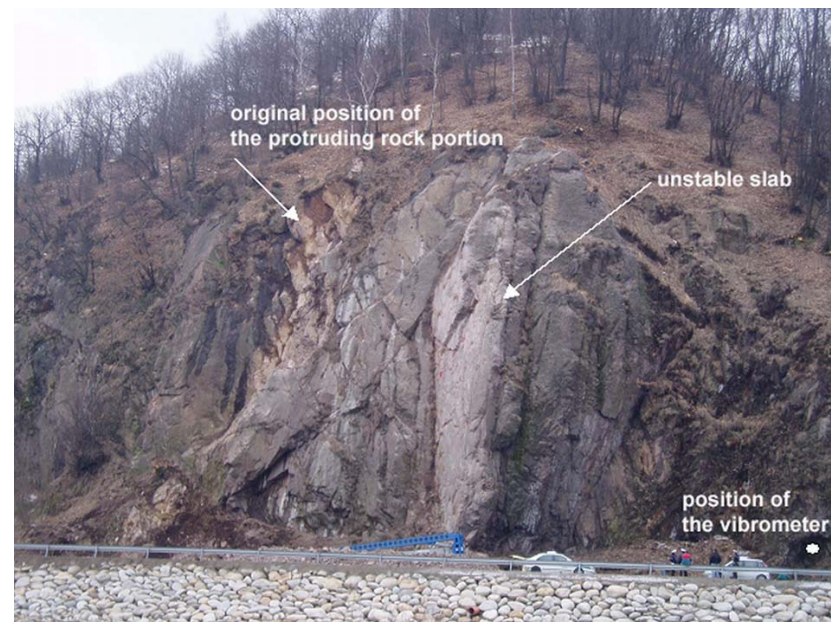

Fig. 8. Front view of the area of case history 2 with the position of the blasted volumes.

a road with a high traffic density of more than $1 \mathrm{car} / \mathrm{min}$. An unstable rock protrusion was also located nearby the monolith with a size of about $100 \mathrm{~m}^{3}$ (Figs. 7 and 8). The monolith was totally isolated from the rock mass of the slope by two open joints $\left(k_{1}=55 / 86\right.$ and $\left.k_{2}=15 / 59\right)$ and its base was an irregularly and highly fractured rock portion. The probability of occurrence of a sudden collapse of the slab was very high.

To eliminate the risk to the roadway, it was possible to stabilize the slab and the protruding mass in place or to demolish them. Since the stabilization of the rock volumes with bolts was very expensive the best solution was to blast the two volumes.

The blast rounds were designed taking into account the limitation of the instantaneous charge to be blasted for each delay, the use of a reliable non-electric explosive system, and a good fragmentation of the blasted rock.

The blast was designed according to the "powder factor" criterion. For the slab, the charges where arranged almost perpendicularly to the back discontinuity with a "powder factor" of $0.24 \mathrm{~kg} / \mathrm{m}^{3}$ while for the protruding volume the holes were arranged with a fan geometry and the delays were set to blast using vertical lines from the most external to the most internal hole, with a "powder factor" of $0.32 \mathrm{~kg} / \mathrm{m}^{3}$.

The number of 38 holes for the protruding mass was with a specific drilling equal to $1.02 \mathrm{~m} / \mathrm{m}^{3}$ while for the slab the holes were 204 with a specific drilling of $0.75 \mathrm{~m} / \mathrm{m}^{3}$. The blast parameters used are in good agreement with those used for the demolition of a rock wedge of $800 \mathrm{~m}^{3}$ threatening the Quebec motorway (Canada) where a powder factor of $0.77 \mathrm{~kg} / \mathrm{m}^{3}$ and a specific perforation of $0.386 \mathrm{~m} / \mathrm{m}^{3}$ were used (Dorval, 1993). The triggering of the round was obtained using the Nonel system (Figs. 9 and 10).

The entire drilling was performed for both locations in one day using both specialized workers suspended by rope and by an aerial platform on a crane with an arm of over $70 \mathrm{~m}$ long. 


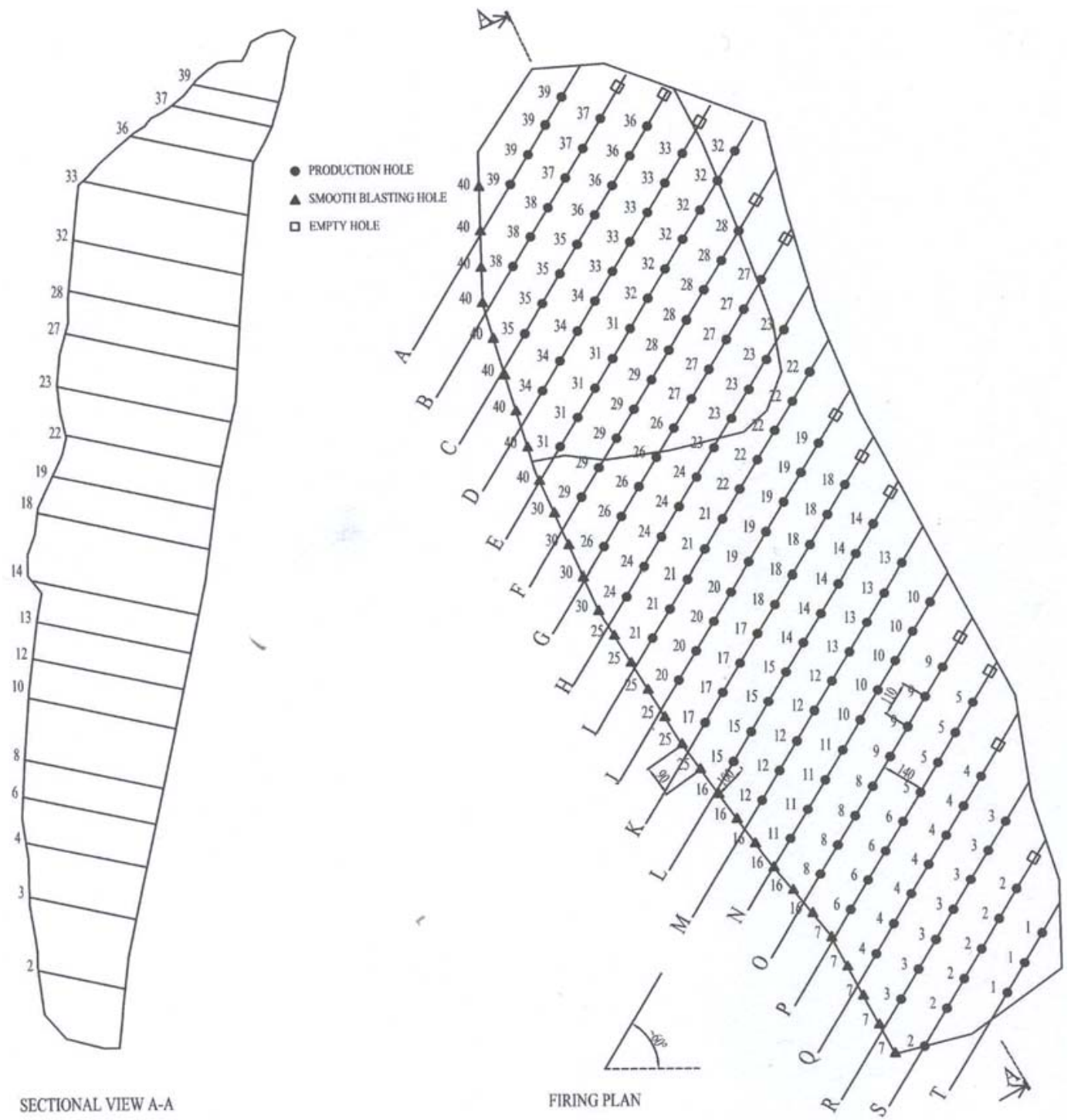

Fig. 9. Front view and cross sections of the used blast round for the unstable slab.

Mixed charges of slurry and gelatine dynamite in cartridges were used for the charging. The typical charge of a borehole consisted of 1 to 2 gelatine dynamite cartridges (booster) at the bottom of the hole, a quantity of slurry (varied in function with the length of the borehole) and $1 \mathrm{~m}$ to $1.6 \mathrm{~m}$ of sand stemming. To facilitate the charging phase each charge was pre-prepared in a PVC pipe and was inserted into the hole (Fig. 11).

The good profiling result was due to the high number of boreholes and the control of vibrations; a maximum instantaneous charge of $5 \mathrm{~kg}$ was used. The values of PPV measured by a vibrometer positioned on the slopes at a distance of $15 \mathrm{~m}$ from the geometrical center of the unstable slab did not exceed $8 \mathrm{~mm} / \mathrm{s}$.

\section{Conclusions}

The demolition of unstable rock volumes by explosives to reduce the risk of collapse from rock slopes is a technique which can be cheaper and faster when compared to the use of reinforcing elements, net fences and/or protection embankments. The examples that have been discussed show that with an accurate preliminary geotechnical study and with a detailed blast design, the drill and blast option can be an appropriate solution to complex and difficult stability problems on rock slopes.

The variability of local situations (geometry, topography, joint set layout, etc.) prevents the formation of a general schematic blasting round but the design must be therefore developed by blasting specialists taking into consideration the following criteria: 


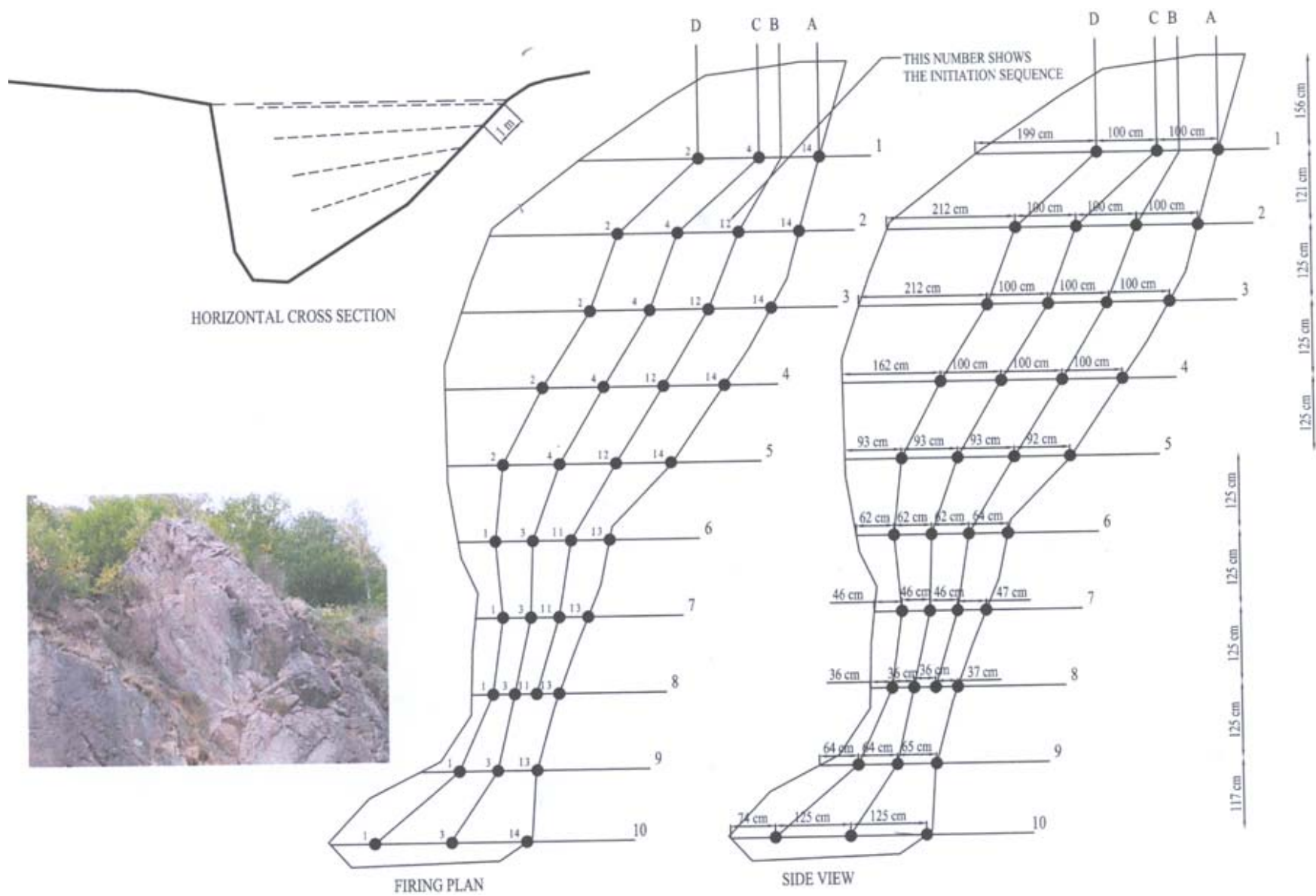

Fig. 10. Front view and cross sections of the used blast round for the protruding rock mass.

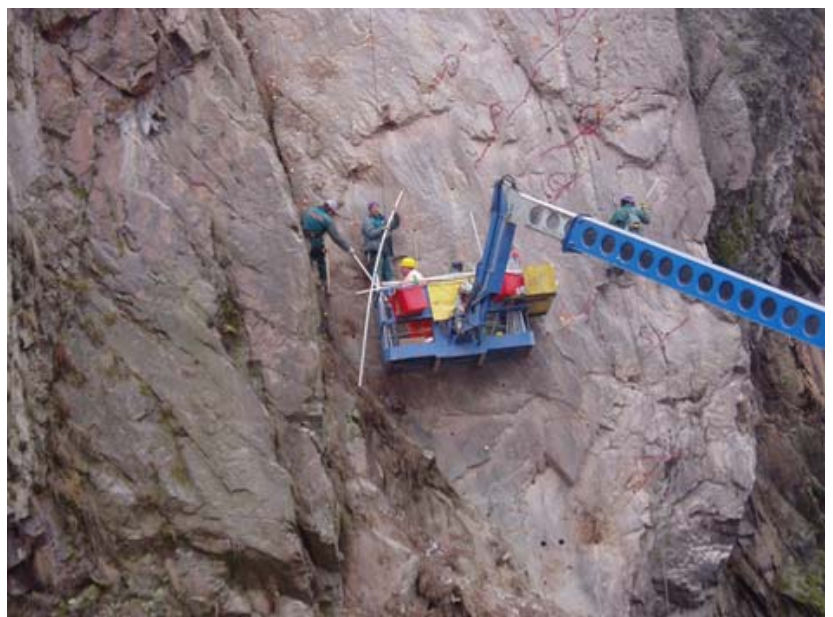

Fig. 11. Charging phase using a mobile platform. The charges were pre-prepared inside a PVC pipe to facilitate ease of placement into the drill holes.

- limitation of the instantaneous charge to be blasted for each delay to avoid blast vibrations that could unstabilize an existing rock portion on a nearby slope;
- use of a reliable triggering system since a failure in the detachment of the rock mass or the presence of unblasted charges inside the muck can create very critical and dangerous situations that can be difficult to be corrected;

- fragmentation of the blasted material into small pieces that can easily be mucked without causing excessive damage to the existing infrastructure, which is often protected using a soft soil mattress;

- prevention and control of flyrock.

The key challenge is usually the definition of the geometrical and geostructural condition of the volumes to be removed in such a way as to correctly locate the round holes. Normally a high specific drilling value is used both to reduce the quantity of instantaneous charge and to obtain a high fragmentation and the powder factor criteria is usually used for the design of the charge. The used powder factor values are similar to those currently employed in quarries. 
Acknowledgements. The Authors want to thank S. Pelizza and R. Mancini of the Politecnico di Torino for the suggestions given to the development of this work. A special thanks is given to Vercelli District (Italy) that allowed the publication of the case histories data and to L. Piek for the suggestions and for the revision of the text.

The financial support for this research was provided by the Italian Ministry for University and Research within the framework of the National Research Program: PRIN-2005 n. 2005085322_002.

The authors contributed equally to this work.

Edited by: F. Guzzetti

Reviewed by: G. Wieczorek and two other anonymous referees

\section{References}

Berta, G.: Esplosioni controllate per la bonifica di massi pericolanti, Quarry \& Construction, 5,PEI, Parma, 2000, (in Italian).

Cardu, M., Oggeri, C., Peila, D., and Casale, M.: Bonifiche con esplosivo, Proceedings of the Conference: "Bonifica di versanti rocciosi per la protezione del territorio", Trento, GEAM, Torino, 251-278, 2004, (in Italian).

Crosta, G. B. and Agliardi, F.: A methodology for physically based rockfall hazard assessment, Nat. Hazards Earth Syst. Sci., 3, 407-422, 2003, http://www.nat-hazards-earth-syst-sci.net/3/407/2003/.

DeWall, R.: Paul Muehl Leaves Blaster's Legacy at Crazy Horse Memorial, J. Expl. Eng., 13, 6-14, 1996.

Dorval, P.: Abattage d'un diedre rocheux instable, Route 155 Grandes Piles (Québec), Proceeding of the Conference: Abattage des Roches à l'Explosif, Alès (France), 538-557, 1993 (in French).

Duncan, C. W. and Norman, I. N.: Stabilization of rock slopes. Landslides investigations and mitigation, Special Report 247, Transportation Research Board, National Research Council, Washington, 474-506, 1996.

Evans, S. G. and Hungr, O.: The assessment of rockfall hazard at the base of talus slopes, Can. Geotech. J., 30, 620-636, 1993.

Giani, G. P.: Rock Slope Stability Analysis, Balkema, Rotterdam, 1992.

Goumans, C. and Wallace, D.: I-40 Rockslide Causes Mountains of Problems, J. Expl. Eng., 16, 8-17, 1999.

Guzzetti, F., Reichenbach, P., and Wieczorek, G. F.: Rockfall hazard and risk assessment in the Yosemite Valley, California, USA, Nat. Hazards Earth Syst. Sci., 3, 491-503, 2003, http://www.nat-hazards-earth-syst-sci.net/3/491/2003/.

Langefors, U. and Kihlstrom, B.: The modern technique of rock blasting, J. Wiley and Sons, New York, 1967.
Locatelli, L.: Analisi del rischio di caduta massi lungo un tratto della Gardesana Occidentale; Geoingegneria Ambientale e Mineraria, GEAM, XLII (1), 33-44, 2005.

Mackenzie, D.: State Highway 6 on the Nevis Bluff, Queenstown, New Zealand, J. Expl. Eng., 21, 40-41, 2004.

Mancini, R. and Cardu, M.: Powder factor and geometry in blast design. Int. Seminar on Rock Excavation Engineering-Present and future trends, Goa, India, A-XII-1-A-XII-11, 1995.

Mancini, R. and Cardu, M.: Scavi in roccia - Gli esplosivi, Hevelius Ed., Benevento, 2001, (in Italian).

McCauley, M., Works, B., and Naramore, S.: Rockfall mitigation, Report FHWA/CA/TL-85/12, U.S. Department of Transportation, 1-147, 1985

Melnikov, N. and Chesnokov, M.: Safety in Opencast Mining, Mir Publishers, Moscow, 1969.

Oggeri, C. and Peila, D.: Protections of transportation systems against rockfalls, $8^{\text {th }}$ International Symposium on Landslide: "Landslide in the research, theory and practice", Cardiff, Thomas Telford, London, 1141-1146, 2000.

Peckover, F. L. and Kerr, W. G.: Treatment and maintenance of rock slopes on transportation routes, Can. Geotech. J., 14, 487-507, 1977.

Peila, D., Pelizza, S., and Sassudelli, F.: Evaluation of behaviour of rockfall restraining nets by full scale tests, Rock Mechanics and Rock Engineering, Springer-Verlag, 31, 1-24, 1998.

Peila, D., Oggeri, C., and Baratono, P.: Barriere paramassi a rete, GEAM, Torino, 2006 (in Italian).

Peila, D., Oggeri, C., and Castiglia, C.: Ground reinforced embankments for rockfall protection: design and evaluation of full scale tests, Landslides, Springer-Verlag, 4, 255-265, 2007.

Pelizza, S., Peila, D., and Oggeri, C.: Tipologie di intervento per la bonifica di versanti rocciosi, Conference: "Bonifica di versanti rocciosi per la protezione del territorio", Trento, GEAM, Torino, 9-44, 2004, (in Italian).

Philippon, N.: Trim Blasting and Slope Stabilization at the Sea to Sky Highway in British Columbia, J. Expl. Eng., 18, 5, 9-33, 2001.

Rotzetter, G.: Beseitigung der Bergsturzgefahr am Kirchberg in Meiringen (Schweiz) durch Sprengarbeit, Nobel Hefte, 43, 101106, 1977 (in German).

Wieczorek, G. F., Stock, G. M., Reichenbach P., Snyder, J. B. Borchers, J. W., and Godt, J. W.: Investigations and hazard assessment of the 2003 and 2007 Staircase Falls rock falls, Yosemite National Park, California, USA, Nat. Hazards Earth Syst. Sci., 8, 421-432, 2008, http://www.nat-hazards-earth-syst-sci.net/8/421/2008/.

Woolf, R. and Goumans, C.: Rock Slope Remediation on the Pennsylvania Turnpike, J. Expl. Eng., 19, 8-17, 2002. 